\title{
Development situations and performance evaluation of Chinese government guide funds
}

\author{
Zhao Liu a*, Cong Qiaob \\ a Shaanxi Financial Holding Group Co., Ltd, Shaanxi, China. \\ b China CITIC Bank Corporation Limited, School of Economics and Finance, Xian Jiaotong University, Xian, China. \\ ${ }^{*}$ Corresponding author's email address: kairoc@stu.xjtu.edu.cn
}

\begin{tabular}{ll}
\hline A R T I C L E I N F O & A B S T R A C T \\
\hline $\begin{array}{l}\text { Received: 30-11-2016 } \\
\text { Accepted: 01-01-2017 }\end{array}$ & $\begin{array}{l}\text { Now, structural contradictions in China's industrial development are prominent. } \\
\text { Government guide fund, as a new investment and financing tool, bears high expectations } \\
\text { of the government on promoting industrial restructuring. In recent years, Chinese } \\
\text { Government guide funds have entered the rapid development stage. However, the post- } \\
\text { investment performance management and other assessment indicators still need to be }\end{array}$ \\
$\begin{array}{l}\text { Keywords: } \\
\text { Analytic hierarchy process; } \\
\text { Government guide funds; }\end{array}$ & $\begin{array}{l}\text { improved. This paper firstly introduced Chinese Government guide funds from different } \\
\text { perspectives; secondly built a performance assessment indicator system for Shaanxi } \\
\text { Performance evaluation. }\end{array}$ \\
$\begin{array}{l}\text { Province based on the current situation of Shaanxi's government guide fund. This paper } \\
\text { suggested introducing government guide fund into the performance assessment system, } \\
\text { which presents a new thought for standardization and normative administration of } \\
\text { gevernment guide fund. }\end{array}$ \\
\hline
\end{tabular}

(C) 2016 The Authors. This is an open access article under the terms of the Creative Commons Attribution License 4.0, which allows use, distribution and reproduction in any medium, provided the original work is properly cited.

DOI: http://dx.doi.org/10.18533/jefs.v5i01.266

ISSN 2379-9463(Print), ISSN 2379-9471(Online)

\section{Development status quos of government guide funds in China}

\subsection{Establishment conditions of government guide funds}

By the end of December, 2015, in total, 780 domestic Government guide funds had been established, and the size of the funds reached CNY 2183.447 billion. Among the above funds, the quantity of Government guide funds that was newly established in 2015 was 297, and the size of the funds was CNY 1508.996 billion, being 2.83 times of the guiding fund quantity and 5.24 times of the size of the funds in 2014 , respectively.

At the central level, in 2015, two major funds were newly established: one was the National Venture Capital Guiding Fund for Emerging Industries with a total size of CNY 40 billion, guiding a capital of more than CNY 180 billion from all aspects of the society to participate, and it would establish a strategic emerging industry board in the Shanghai Stock Exchange; the other was the National Small and Medium Enterprise (SME) Development Fund with a total size of CNY 60 billion, leveraging with a social capital of more than CNY 100 billion. At the local level, along with the defined posture that the central encouraged the development of Government guide funds, various Government guide funds established by various local governments emerged in large numbers like spring bamboo shoots after rain, across various fields such as science and education, culture, industrial investment and others, and a number of thematic funds such as the Silk Road Fund, the Public-Private Partnerships (PPP) Fund, the Cultural and Creative Investment Fund, the Industrial Guiding Fund and others emerged. 


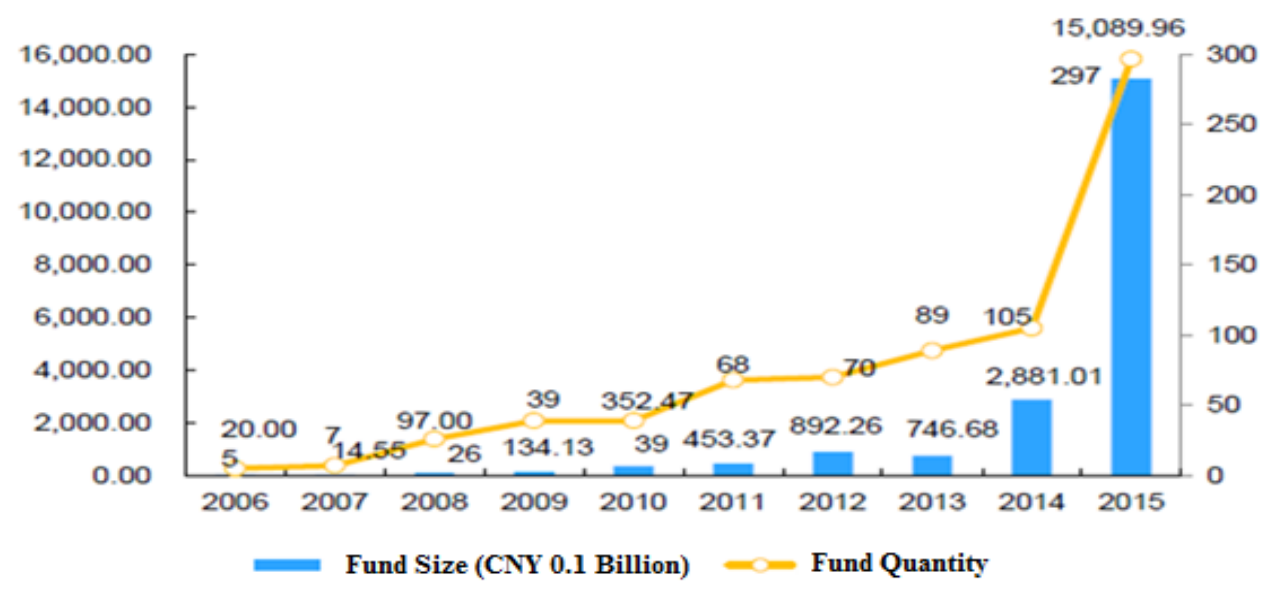

Figure 1: Comparison of the establishment conditions of government guide funds from 2006 to 2015

Table 1: List of a part of central-level government guide funds

\begin{tabular}{llr}
\hline Guiding & Establishment & Targeted \\
Government & Time & Size \\
Fund Name & & (CNY 0.1 \\
& & Billion) \\
\hline
\end{tabular}

National SME September,

Development 2015

Fund

National

Venture Capital

Guiding Fund

for Emerging

Industries

$\begin{array}{ll}\text { National } & \text { September, } \\ \text { Integrated } & 2014 \\ \text { Circuit Industry } & \\ \text { Investment } & \\ \text { Fund (NICIIF) } & \end{array}$

SME

Development

January, 2012

Fund

National

Scientific and

Technological

Achievements

Transformation

Guiding Fund

July, 2011

Technological July, 2007

SME Venture

Capital Guiding

Fund
600 Determined and established by the State Council's executive meetings after research. The central finance funded CNY 15 billion through integrating capitals. This fund will focus on and support SMEs that are in the "seed period" and the initial start-up period through the establishment of "mother" funds, direct investment funds and others.

400 Combined the Special Fund for the Development of Strategic Emerging Industries of the central finance with the Central Infrastructure Construction Investment Fund, and others, and would use their funds. Mainly invests in innovative enterprises that are in the early and middle period, and the initial start-up period, in the emerging industries.

1387 National finance accounted for CNY 36 billion, the China Development Bank Capital Corporation Ltd. (CDBC) accounted for CNY 32 billion, the Beijing E-Town International Investment \& Development Co., Ltd. (E-Town Capital) accounted for CNY 10 billion representing Beijing City and the Beijing Economic and Technological Development Zone, and the remainder CNY 42 billion would be raised from the market. This fund mainly invests in chip manufacturing and other key industries.

150 Funded and established by the central finance. The targeted size was CNY 15 billion. It is mainly used to support the development of small and micro enterprises in the initial start-up period. From 2012, annually arranged CNY 3 billion for 5 years.

This fund is mainly used to support the transformation and exploitation of financial-capital-formed scientific \& technological achievements including national (industrial and departmental) scientific \& technological plans (special projects and projects), local scientific \& technological plans (special projects and projects), and other new technology, products, crafts, materials, devices and their systems, and others produced by public institutions.

The maximum shareholding ratio of guiding funds could not be more than $25 \%$ in the paid-up capital (or investment amount) of venture capital enterprises, and could not become the largest shareholder. The guiding fund could make a follow-up investment with a proportion of less than $50 \%$ of the actual investment amount of the venture capital institution, and the amount for each 
project could not be more than CNY 3 million. The guiding fund could offer a venture grant with a proportion of less than $5 \%$ of the actual investment amount of the venture capital institution, and the amount of the grant could not be more than CNY 5 million.

\subsection{Geographical distribution of government guide funds}

With respect to the regional distribution of the Government guide funds of China, the development momentum of Government guide funds of Beijing City, Shanghai City, Shenzhen City, and cities of which the development of venture capital (VC)/ private equity (PE) is good in Jiangsu Province and other regions, is strong. Moreover, some second-tier cities that densely gather nongovernmental enterprises and industrial parks also one after another followed up and established Government guide funds to support the development of local industries. Generally speaking, in the economically-developed eastern regions, guiding funds were densely established, while in the economically underdeveloped regions in the central and western counterparts, the quantity of established guiding funds is relatively low. Specifically speaking, in China, Jiangsu Province and Zhejiang Province are provinces that have most densely established Government guide funds and have densely gathered a large number of guiding funds at the prefecture, the city, the district, and the county levels.

In the region around the Bohai Sea, Beijing City, Tianjin City, and regions in Shandong Province have established more guiding funds. In the central and western regions, the start time of guiding funds was late; however, in recent several years, they have also gradually been active. Hubei Province, Sichuan Province, Shaanxi Province, and the Inner Mongolia Autonomous Region are regions where quantities of established guiding funds are high and guiding funds with sizes of more than CNY 1 billion gradually emerged. Remote regions also established Government guide funds. For example, Tibet Autonomous Region, in 2012, established the Venture Capital Guiding Fund of the Tibet Autonomous Region; the Xinjiang Uygur Autonomous Region established the Scientific \& Technological Venture Capital Fund of the Xinjiang Uygur Autonomous Region, and Urumqi City Guiding Investment Fund for Scientific \& Technological SMEs; the Guangxi Zhuang Autonomous Region established the Nanning City Guiding Fund for the Guangxi Beibu Gulf Economic Zone (BGEZ); and the Ningxia Hui Autonomous Region, in 2014, established the Guiding Government Fund of the Ningxia Hui Autonomous Region.

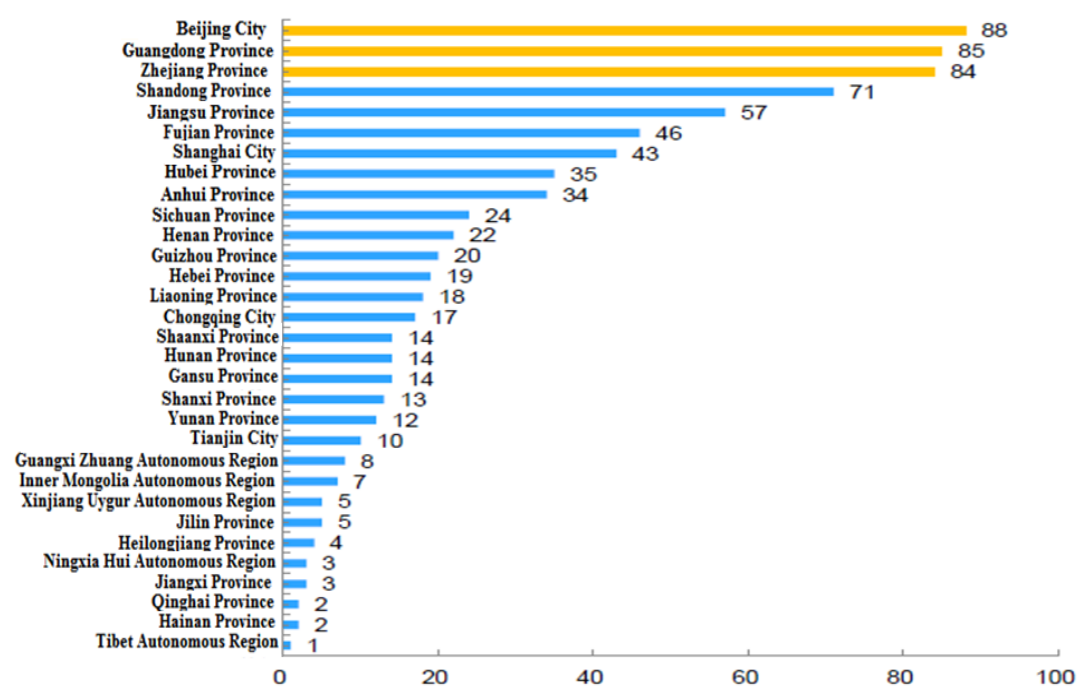

Figure 2. Geographical distribution condition of government guide funds in the end of 2015 (with Respect to Quantities of Funds: piece)

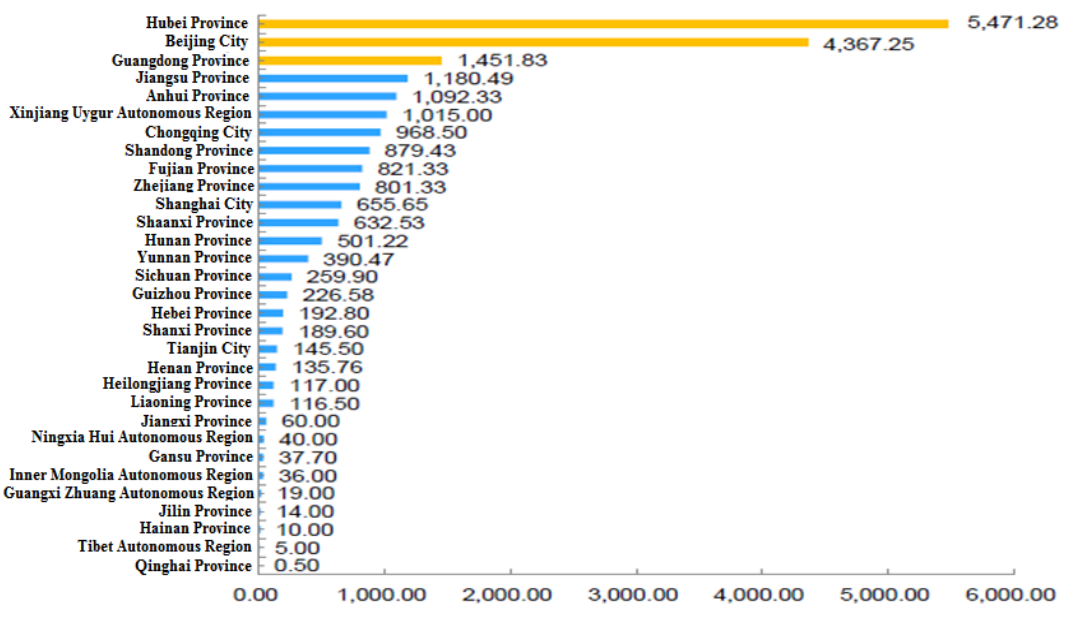

Figure 3. Geographical distribution condition of government guide funds in the end of 2015 (with respect to sizes of funds, CNY 0.1 Billion)

Currently, Government guide funds of China have already formed characteristics of the distribution with the Yangtze River Delta region and the region around the Bohai Sea as the gathering area and full spread from the eastern coastal regions to the central and western regions. The central and western regions become the new fertile soil for establishing Government guide funds. Moreover, Government guide funds have a trend that they will gradually spread to the district and the county levels. The Yangtze River Delta region is especially typical. This 
region of which all the districts and counties gather a large number of SMEs, is the gathering site of enterprises of which development funds are lacking and in a tense situation. This region is also the source of capital needs. Therefore, the necessity of establishment exists.

With respect to the quantity of established funds, the Beijing City region has cumulatively established 88 Government guide funds and is first ranked among all the regions. Furthermore, guiding funds in the regions of Guangdong Province and Zhejiang Province are relatively actively established with the quantities of funds of 85 and 84, respectively. With respect to the sizes of the established funds, Hubei Province is stably first ranked among all the provinces with a size of CNY 547.128 billion. Beijing City and Guangdong Province closely follow it with fund sizes of 436.725 billion and 145.183 billion, respectively.

\section{Performance evaluation of government guide funds-taking Shaanxi province as an example}

In recent several years, the development sizes of Government guide funds of China have been bigger and bigger. However, with respect to specific conditions of different Government guide funds, it is still highly differential. Therefore, to establish an accurate and effective set of index systems suitable for the performance evaluation of Government guide funds of China becomes the urgent need in integrating guiding funds into the public financial assessment and evaluation system, and also the inevitable demands in the further enhancement of policy and guiding effects of Government guide funds, and the promotion for better and faster development of guiding funds.

\subsection{Constitution of performance indexes of guiding funds}

The index system for the performance evaluation of guiding funds is composed of three main aspects: policy aims, policy effect and operation management capability. Explanation for specific evaluation indexes is as follows:

\section{(1) Policy aims}

Guiding funds fundamentally are "policy funds", intend to bring leverage/amplification effects of financial capitals into play, encourage funds to invest in local agencies' industrial supported projects, and promote the development of local economy. The performance evaluation of guiding funds must assess whether they have realized aims at the beginning of establishment. This article selected two policy aim indexes that separately were industrial support and guiding effect, and whether Guiding funds preferentially invest in the local enterprises.

\section{a. Industrial support and guiding effect}

Developing strategic emerging industries, promoting the adjustment and upgrade of industrial structures, and realizing the transformation of economic growth patterns is the national economic development strategy and development aims mentioned in the "Norms of the Thirteenth Five-year Plan" of Shaanxi province. Funds established by Shaanxi Province are just, through guiding funds, for promoting the development of the six major pillars of Shaanxi province and fourteen industries, enhancing the independent innovation capability of Shaanxi province, developing a batch of innovative enterprises with the market as the guiding orientation, with independent research and development as the force, and helping promote the economic development of our province. Evaluation of this aspect can be started from two aspects: whether guiding funds focus on and invest in industrial fields that agencies support and encourage, and whether there are professional investment fields that they play extra emphasis on.

\section{b. Whether they preferentially invest in the local enterprises}

In the establishment of guiding funds, Shaanxi Province clearly define that a certain proportion of funds need to be invested in local enterprises to promote the economy of Shaanxi Province. It is also one of the policy aims of guiding funds. Therefore, "whether they preferentially invest in the local enterprises" is made an index to assess the policy aims.

\section{(2) Policy effect}

The policy effect index refers to the index to assess the operation result of guiding funds and their impact on the society, mainly includes economic and social benefits.

\section{(3) Operation management capability}

The standard to measure the operation management capability is mainly for the levels of the organization. Assessment is conducted mainly from two aspects: sustainable management capability, risk control capability. 
Table 2. Initial index system set for the performance evaluation of guiding funds

\begin{tabular}{|c|c|c|}
\hline First-level Index & Second-level Index & Third-level Index \\
\hline \multirow[t]{3}{*}{ Policy Aims } & Industrial Support and Guiding Effect & $\begin{array}{l}\text { Whether they focus on and invest in industrial fields } \\
\text { that agencies support and encourage? }\end{array}$ \\
\hline & & $\begin{array}{l}\text { Whether there are professional investment fields } \\
\text { that they play extra emphasis on? }\end{array}$ \\
\hline & $\begin{array}{l}\text { Whether They Preferentially Invest in } \\
\text { the Local Enterprises }\end{array}$ & Investment Proportion in the Province \\
\hline \multirow[t]{6}{*}{ Policy Effect } & Economic Benefits & Invested Enterprise Quantity \\
\hline & & Annual Revenue Growth Rate of the Fund \\
\hline & & $\begin{array}{l}\text { Quantity of Projects That They Successfully Exit } \\
\text { from }\end{array}$ \\
\hline & Social Benefits & Payable Taxes of the Fund \\
\hline & & Growth of Sales of the Invested Enterprise \\
\hline & & Growth of Employment of the Invested Enterprise \\
\hline Operation & Sustainable Management Capability & Capital-raising Capability \\
\hline Management & & \\
\hline Capability & Risk Control Capability & $\begin{array}{l}\text { Whether the financial management situation of idle } \\
\text { funds complies with regulations? } \\
\text { Conditions of the Responsibility Implementation of } \\
\text { the Selected Custodian Bank }\end{array}$ \\
\hline
\end{tabular}

\subsection{Determination of weights of indexes}

After determining the index system for performance evaluation, the following issue to be solved is the assignment of weights. Weight is the quantitative express of the relative importance of the index compared with other indexes of all the levels. Weights should be assigned to all the principles and indexes. Compared with the higher-level index, the sum of the weights of its lower-level indexes is generally 1.

\section{(1) Methods to determine weights}

There are many methods to calculate weights such the Expert Consultation \& Determination Method, the Key Element-normalized Quantitative Method, the Comparison between Determined Indexes, the Ring-ratio Quantitative Method for Determined Indexes, the Delphi Expert Consultation Method, the Q Classification Method, the Analytic Hierarchy Process and so on. This article used the last type of method, i.e. the Analytic Hierarchy Process, to develop weights of indexes.

The Analytic Hierarchy Process (AHP) was put forward by American Operational Research Expert and Professor of University of Pittsburgh Satty in 1970s. The AHP has been widely applied in all walks of life domestically and overseas and become the most frequently used Multi-objective Decision-Analysis method. The basic train of thought of the AHP to solve problems is: firstly, make the problem need to be solved hierarchical, divide the problem into different component factors according to the nature of the problem and the overall objective to be achieved, aggregate and combine the factors based on different levels according to the interrelated effects between factors and the affiliation relationship, form a multi-level analysis structure model, and finally analyze the system and attribute it to the issue of the determination of the relative importance-weight of the lowest-level index compared with the highest-level index (overall objective) or the issue of the orders of relatively superior and inferior orders.

Way to determine the weights of all the indexes is to develop a questionnaire about the extents of the impacts of all indexes on their direct upper-level indexes. Through questionnaire, beg experts to score the importance of the index compared with other indexes. According to experts' scoring, process the data with the AHP method.

To obtain original data and information, 12 copies of the questionnaire were distributed to industrial insiders, agency officers in charge of guiding funds, and scholars. The recovery rate was $100 \%$. This article calculated means of weight values suggested by them to provide bases for weight determination, and used the AHP method to calculate the needed original data.

\section{(2) Procedures to determine weights}

When the AHP method is applied to make decisions, generally it can be divided into four stages: 
Analyze the relationship between the factors in the system and establish a hierarchical structure for the system. Conduct the importance comparison between factors at the same level with respect to a certain principle at the directly upper level. Construct a pairwise comparison judgment matrix. The method is: With respect to the principle C, which was more important? Factor i or j? How important were they? Generally, weights were assigned for the importance extents according to the proportional scales 1, 3, 5 and 7 . Table 5 lists meanings of the scales.

Table 3: Meanings of scales of weights for performance indexes

\begin{tabular}{ll}
\hline Scale $\alpha_{i j}$ & Meaning \\
\hline 1 & Means both factors had the same importance. \\
3 & Means the former factor i was slightly more important than the latter factor $\mathrm{j}$. \\
5 & Means the former factor i was significantly more important than the latter factor $\mathrm{j}$. \\
7 & Means the former factor i was strongly more important than the latter factor $\mathrm{j}$. \\
& Let the ratio of the importance of factor i to that of factor $\mathrm{j}$ be $\alpha_{i j}$, then the ratio of the \\
& importance of factor $\mathrm{j}$ to that of factor i was $\alpha_{j i} \alpha_{i j}$
\end{tabular}

\section{a. Determination of local precedence order (Weight)}

After the judgment matrix has been given, the weight $\left\{w_{i}\right\}$ can be determined according to the judgment matrix. There are many methods to solve $\left\{w_{i}\right\}$. The recommended way is to obtain $\left\{w_{i}\right\}$ through solving the maximum eigenvalue $\lambda$ max of the judgment matrix. Generally speaking, the calculation of the maximum eigenvalue of the matrix and corresponding characteristic vector does not require the chase of high accuracy. Because the judgment matrix itself has a considerably wide range of error, this article used an approximation algorithm, i.e. the Square Root Method. The calculation procedure is as follows:

(1) Calculate the multiplying products of factors of each row in the judgment matrix B $M_{i}$

$M_{i}=\prod_{j-1}^{n} b_{i j}, \quad i=1,2, \ldots, \mathrm{n}$.

Calculate the n-th root of $M_{i}$

$\bar{w}_{i}=\sqrt[n]{M_{i}}$

Normalize the vector $\left.\bar{w}=\left(\bar{w}_{1}, \bar{w}_{2}, \ldots-\right)^{T}\right)$, that is:

$$
w=\frac{\bar{w}_{i}}{\sum_{j=1}^{n} \bar{w}_{j}}
$$

Calculate the maximum eigenvalue of the judgement matrix $\lambda$ max :

$$
\lambda \max =\sum_{i-1}^{n} \frac{(B w)_{i}}{n w_{i}}
$$

\section{b. Consistency test of the judgement matrix}

The most key step of the AHP method is the precedence order determined through pairwise comparison, and the quality of the final decision, to a high extent, depends on decision makers' consistency during the pairwise comparison. Based on the AHP theory, Satty deemed that the measurement of the consistency of the judgement matrix could be conducted by the calculation of the consistency ratio (CR). When $C R<0.10$, it is deemed that the consistency of the judgement matrix is satisfactory. Otherwise it is needed to adjust the judgment matrix and make its consistency satisfactory. It can be obtained through the following formula: 
$C I=\frac{\lambda \max -n}{n-1}$

$C R=\frac{C I}{R I}$

Wherein, CI is consistency index, $\lambda$ max is the maximum eigenvalue of the judgement matrix and RI is the Random Index and the random and general index of the judgement matrix. RI Value Table:

Table 4: Compatibility test

\begin{tabular}{lrrrrrrr}
\hline order & 1 & 2 & 3 & 4 & 5 & 6 & 7 \\
\hline RI & 0.00 & 0.00 & 0.58 & 0.90 & 1.12 & 1.24 & 1.32
\end{tabular}

a. Calculate weights of factors at all the levels based on their impacts on the objective next to the directly upper one and calculate the weight of the lowest-level factor to the overall objective of the system and determine the sequence.

\section{(3) Calculation of weights of all the indexes}

a. Weights of first-level indexes

According to the principle of the AHP, construct a pairwise comparison matrix for the first-level indexes A1, A2, and $\mathrm{A} 3$, determine weights of the indexes, the judgement matrix is:

$$
A=\left[\begin{array}{ccc}
1 & 0.67 & 0.83 \\
1.5 & 1 & 1.8 \\
1.2 & 0.56 & 1
\end{array}\right]
$$

Multiplying product of factors of each row in the judgement matrix A: $M_{i}=\left[\begin{array}{lll}0.56 & 2.7 & 0.67\end{array}\right]^{T}$

The n-th root of $M_{i}: \bar{W}_{i}^{-}=\left(\begin{array}{lll}0.82 & 1.39 & 0.87\end{array}\right)^{T}$

The normalization of the vector $\mathcal{W}_{i}$ results in the characteristic vector: $\begin{array}{lll}w=\left(\begin{array}{lll}0.27 & 0.45 & 0.28\end{array}\right)^{T}\end{array}$

Calculate the maximum eigenvalue $\lambda \max =3, C I=\frac{\lambda \max -n}{n-1}=$, after checking Table 6, it is found that: $\mathrm{RI}=0.58$

Calculate the consistency index: $C R=\frac{C I}{R I}=0<0.1$, it meets the requirement of consistency.

b. Weights of Second-level Indexes

(1) Construct a pairwise comparison matrix for B1, B2, determine weights of the indexes, the judgement matrix is: $B=\left[\begin{array}{cc}1 & 0.56 \\ 1.8 & 1\end{array}\right]$

Multiplying product of factors of each row in the judgement matrix B: $M_{i}=\left[\begin{array}{ll}0.56 & 1.8\end{array}\right]^{T}$

The n-th root of $M_{i}: \overline{\mathcal{W}}_{i}=\left(\begin{array}{ll}0.75 & 1.34\end{array}\right)^{T}$

The normalization of the vector $\mathcal{W}_{i}$ results in the characteristic vector: $\quad w=\left(\begin{array}{ll}0.36 & 0.64\end{array}\right)^{T}$

Calculate the maximum eigenvalue $\lambda \max =3, C I=\frac{\lambda \max -n}{n-1}=0$, after checking Table 6, it is found that: $\mathrm{RI}=0.58$

Calculate the consistency index: $C R=\frac{C I}{R I}=0<0.1$, it meets the requirement of consistency.

(2) Construct a pairwise comparison matrix for B3, B4, determine weights of the indexes, the judgement matrix is: 


$$
B=\left[\begin{array}{cc}
1 & 1.5 \\
0.67 & 1
\end{array}\right]
$$

Multiplying product of factors of each row in the judgement matrix B: $M_{i}=\left[\begin{array}{ll}1.5 & 0.67\end{array}\right]^{T}$

The n-th root of $M_{i}: \quad \bar{w}_{i}=\left(\begin{array}{ll}1.22 & 0.82\end{array}\right)^{T}$

The normalization of the vector $\overline{\mathcal{W}}_{i}$ results in the characteristic vector: $w=\left(\begin{array}{ll}0.6 & 0.4\end{array}\right)^{T}$

Calculate the maximum eigenvalue $\lambda \max =3, C I=\frac{\lambda \max -n}{n-1}=0$, after checking Table 6 , it is found that: $\mathrm{RI}=0.58$

Calculate the consistency index: $C R=\frac{C I}{R I}=0<0.1$, it meets the requirement of consistency.

(3) Construct a pairwise comparison matrix for B5, B6, determine weights of the indexes, the judgement matrix is: $B=\left[\begin{array}{cc}1 & 0.69 \\ 1.45 & 1\end{array}\right]$

Multiplying product of factors of each row in the judgement matrix B: $M_{i}=\left[\begin{array}{ll}0.69 & 1.45\end{array}\right]^{T}$

The n-th root of $M_{i}: \bar{W}_{i}=\left(\begin{array}{ll}0.83 & 1.2\end{array}\right)^{T}$

The normalization of the vector $\overline{\mathcal{W}}_{i}$ results in the characteristic vector: $\quad w=\left(\begin{array}{ll}0.41 & 0.59\end{array}\right)^{T}$

Calculate the maximum eigenvalue $\lambda \max =4, C I=\frac{\lambda \max -n}{n-1}=0$, after checking Table 6 , it is found that: $\mathrm{RI}=0.58$

Calculate the consistency index: $C R=\frac{C I}{R I}=0<0.1$, it meets the requirement of consistency.

c. Weights of third-level indexes

(1) Construct a pairwise comparison matrix for $\mathrm{C} 1, \mathrm{C} 2$, determine weights of the indexes, the judgement matrix is: $C=\left[\begin{array}{cc}1 & 3 \\ 0.33 & 1\end{array}\right]$

Multiplying product of factors of each row in the judgement matrix C: $M_{i}=\left[\begin{array}{ll}3 & 0.33\end{array}\right]^{T}$

The n-th root of $M_{i}: \bar{W}_{i}=\left(\begin{array}{ll}1.73 & 0.58\end{array}\right)^{T}$

The normalization of the vector $\overline{\mathcal{W}}_{i}$ results in the characteristic vector: $w=\left(\begin{array}{ll}0.75 & 0.25\end{array}\right)^{T}$

Calculate the maximum eigenvalue $\lambda \max =3, C I=\frac{\lambda \max -n}{n-1}=0$, after checking Table 6 , it is found that: $\mathrm{RI}=0.58$

Calculate the consistency index: $C R=\frac{C I}{R I}=0<0.1$, it meets the requirement of consistency.

(2) Construct a pairwise comparison matrix for $\mathrm{C} 4, \mathrm{C} 5, \mathrm{C} 6$, determine weights of the indexes, the judgement matrix is: $C=\left[\begin{array}{ccc}1 & 0.33 & 0.2 \\ 3 & 1 & 0.33 \\ 5 & 3 & 1\end{array}\right]$

Multiplying product of factors of each row in the judgement matrix C: $M_{i}=\left[\begin{array}{lll}0.07 & 1 & 15\end{array}\right]^{T}$ 
The n-th root of $M_{i}: \bar{w}_{i}=\left(\begin{array}{lll}0.41 & 1 & 2.47\end{array}\right)^{T}$

The normalization of the vector $\overline{\mathcal{W}}_{i}$ results in the characteristic vector: $w=\left(\begin{array}{lll}0.1 & 0.26 & 0.64\end{array}\right)^{T}$

Calculate the maximum eigenvalue $\lambda \max =3, \quad C I=\frac{\lambda \max -n}{n-1}=0.005$, after checking Table 6 , it is found that: $\mathrm{RI}=0.00$

Calculate the consistency index: $C R=\frac{C I}{R I}=0<0.1$, it meets the requirement of consistency.

(3) Construct a pairwise comparison matrix for $\mathrm{C} 7, \mathrm{C} 8, \mathrm{C} 9$, determine weights of the indexes, the judgement matrix

is: $C=\left[\begin{array}{ccc}1 & 0.14 & 0.2 \\ 7 & 1 & 3 \\ 5 & 0.33 & 1\end{array}\right]$

Multiplying product of factors of each row in the judgement matrix C: $M_{i}=\left[\begin{array}{lll}0.03 & 21 & 1.67\end{array}\right]^{T}$

The n-th root of $M_{i}: \bar{W}_{i}=\left(\begin{array}{lll}0.31 & 2.76 & 1.19\end{array}\right)^{T}$

The normalization of the vector $\overline{\mathcal{W}}_{i}$ results in the characteristic vector: $\begin{array}{lll}w=\left(\begin{array}{lll}0.07 & 0.65 & 0.28\end{array}\right)^{T}\end{array}$

Calculate the maximum eigenvalue $\lambda \max =3, C I=\frac{\lambda \max -n}{n-1}=0.01$, after checking Table 6 , it is found that: $\mathrm{RI}=0.00$

Calculate the consistency index: $C R=\frac{C I}{R I}=0<0.1$, it meets the requirement of consistency.

(4) Construct a pairwise comparison matrix for $\mathrm{C} 11, \mathrm{C} 12$, determine weights of the indexes, the judgement matrix is: $C=\left[\begin{array}{cc}1 & 3 \\ 0.33 & 1\end{array}\right]$

Multiplying product of factors of each row in the judgement matrix C: $M_{i}=\left[\begin{array}{ll}1 & 0.33\end{array}\right]^{T}$

The n-th root of $M_{i}: \bar{w}_{i}=\left(\begin{array}{ll}1.44 & 0.69\end{array}\right)^{T}$

The normalization of the vector $\overline{\mathcal{W}}_{i}$ results in the characteristic vector: $w=\left(\begin{array}{ll}0.68 & 0.32\end{array}\right)^{T}$

Calculate the maximum eigenvalue $\lambda \max =3, C I=\frac{\lambda \max -n}{n-1}=0$, after checking Table 6 , it is found that: $\mathrm{RI}=0.58$

Calculate the consistency index: $C R=\frac{C I}{R I}=0<0.1$, it meets the requirement of consistency.

After the calculation of the AHP method, we obtained the weights at the principle level with respect to the objective level, the weights of the first-level indexes with respect to the direct principle levels, and the weights of the secondlevel indexes with respect to their direct first-level indexes. Since the performance evaluation in this article wanted to finally calculate the total performance scores and the performance scores at the principle levels with the secondlevel indexes, after the previous integration of the weights, we figured out the weights of the second-level indexes with respect to the principle level and the objective level, respectively. In order to see the weights of all the indexes more clearly, this article illustrated the weights at all the principle levels under the objective level, the weights of the directly lower level under the principle level, the weights of the second-level indexes with respect to the objective level and the principle level, in the index system (Figure 12).

\section{Suggestions}

3.1 Improve risk prevention measures for government guide fund. 
In order to get rid of moral hazards and principal-agent problem faced by government funds, government guide fund should be operated in marketization mode by specialized management company. The selected management company should also have certain fund-raising capacity and be able to bear a certain ratio of inferior investment.

The government should entrust specialized bank to manage capital of the guide fund. The bank should open an escrow account for the guide fund. A preliminary supervision procedure of "government supervision organspecialized management company- custodian bank" should be built. The custodian bank transfers capital to the specified account of the project company according to the management company's project investment scheme and order of the government supervision organ. The management company has no direct access to the entrusted capital, which can effectively prevent potential problems. Based on the above, the government authority should review and monitor the guide fund budget and check use of the guide fund.

\subsection{Intensify marketization to enhance operating efficiency of government guide fund.}

To raise operating efficiency of guide fund from all aspects such as fund-raising and investment. The government should firstly insist on marketization of the fund source, and cooperate with market institutions so as to realize resources complementarity and intensify leverage of government fund; secondly, realize marketization of investment strategy, break the existing policy restrictions faced by guide fund, and try to maximize investment income under the condition of fixed risk and minimize investment risk under the condition of fixed income; and thirdly, realize marketization of internal management, and build complete internal control procedures including industry information and database, project screening procedure, basic law clauses and negotiation procedure and risk control procedure.

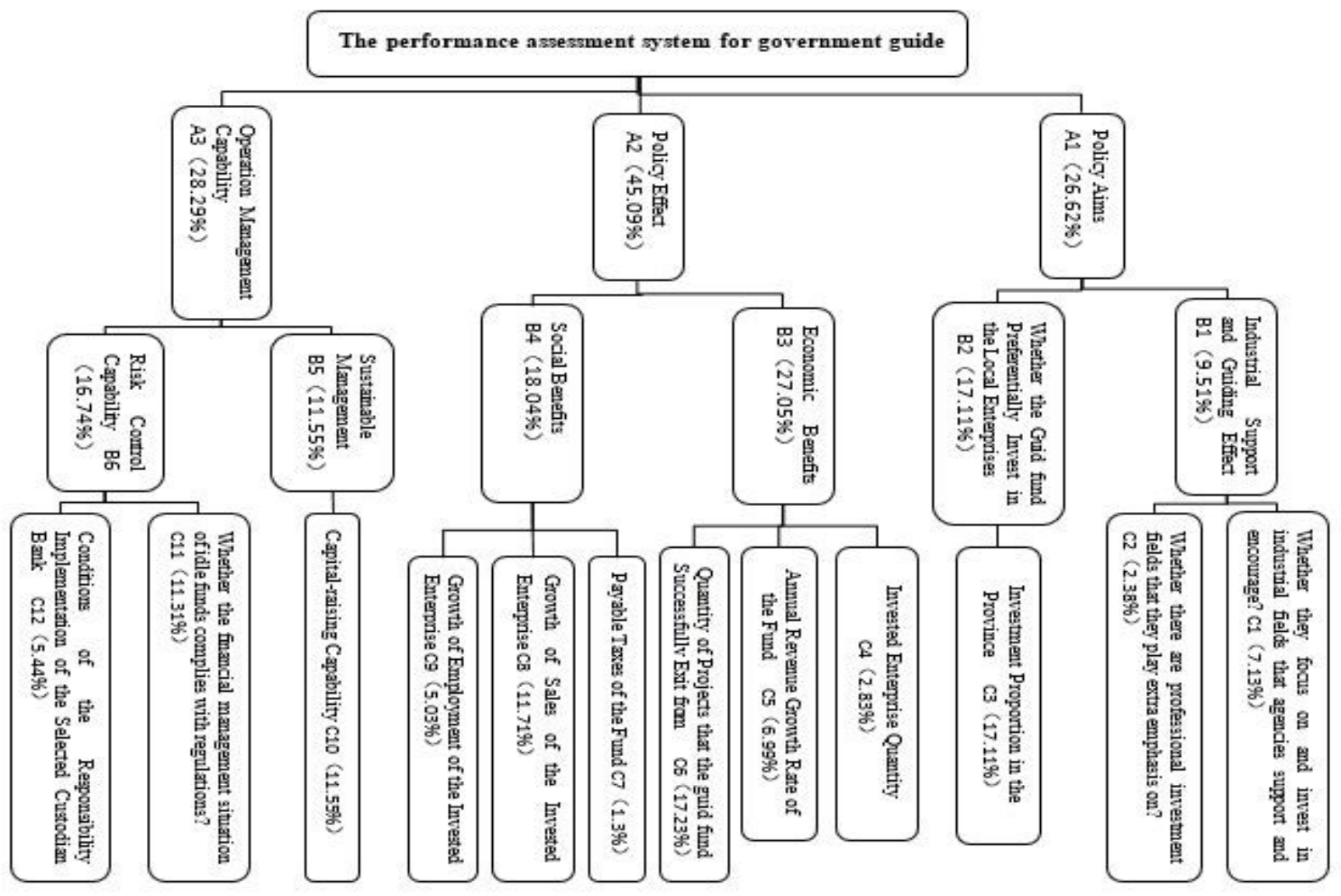

Figure 4: The performance assessment system and the index weight for Shaanxi government guiding fund

\subsection{Establish a sound assessment mechanism}

Both economic benefit and social benefit should be involved in assessment of guide fund in order to realize the objective of guide fund, give full play to the leverage effect of guide fund and make up market defects. To be specific, the assessment elements include investment scale driven by the guide fund, ratio of projects successfully withdrawing, sales growth rate of the invested enterprises, etc. 


\section{References}

Treynor J L. How to rate management investment funds [J]. Harvard Business Review, 1965,43 (January February) : 63-75.

Treynor, Jack, Kay M. Can mutual funds outguess the market? [J].Harvard Business Review, 1966, 44: 131-136.

Jensen M C. The performance of mutual funds in the period 1945-1964[J]. Journal of Finance, 1968, 23 (May): 389416. https://doi.org/10.1111/j.1540-6261.1968.tb00815.x

T. Tykvova, Venture capital in Germany and its impact on innovation, social science research network working paper, DOI:10.2139/ssrn.235512,2014-11-20. https://doi.org/10.2139/ssrn.235512 